\title{
Colheita de medula óssea em cães: modelo para obtenção da fração total de células mononucleares
}

\author{
Bone marrow harvest in dogs: model for acquisition of the total fraction of mononuclears cells
}

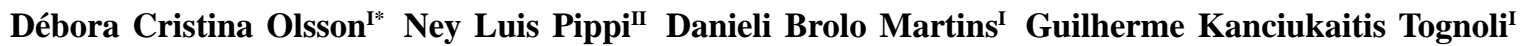 \\ Eduardo de Bastos Santos Júnior ${ }^{I}$ Daniel Curvello Muller ${ }^{\mathrm{I}}$ Sonia Terezinha dos Anjos Lopes ${ }^{\mathrm{II}}$ \\ Francieli Marconato ${ }^{\mathrm{III}}$ Priscilla Domingues Mörchbächer ${ }^{\mathrm{III}}$ Luciele Varaschini Teixeira ${ }^{\mathrm{I}}$
}

\section{RESUMO}

No presente trabalho foi elaborada uma técnica para protocolo de colheita de medula óssea (MO) (10 ml. $\left.\mathrm{kg}^{-1}\right)$, do osso femoral, para isolamento, quantificação e viabilidade da fração total de células mononucleares (CM). Para tanto, 40 cães machos ou fêmeas, sem raça definida, com idade aproximada de dois anos, pesando em torno de $10 \mathrm{~kg}$, foram submetidos a procedimento asséptico em ambiente cirúrgico para colheita de MO. Para a obtenção de uma quantidade suficiente de CM, durante o procedimento foi utilizada a agulha tipo Steis anatômica, que favoreceu a colheita de volume sangüíneo em menor espaço de tempo e não danificou a viabilidade celular. Também foi utilizado o Kit Bone Marrow collection, que teve a finalidade de filtrar as espículas ósseas, mantendo a integridade das CM colhidas durante o período decorrido para o acondiconamento do sangue. Durante o período da colheita de $\mathrm{MO}$, os animais foram submetidos à collheita de sangue periférico (pré, trans e pós-operatório) para avaliações hematológicas e sofreram autotransfusão sangüínea para suprir a queda acentuada de hemoglobina ocorrida nos primeiros momentos da coletaheita. O total de MO colhida e filtrada foi colocado lentamente sob gradiente de densidade Histopaque $\left(1.077 \mathrm{~g} \mathrm{ml}^{-1}\right)$. O material foi centrifugado a $440 \times \mathrm{g}$ por 30 minutos e o anel de células foi colhido, lavado e centrifugado três vezes em meio contendo solução salina 0,9\%, DMEM e soro sangüíneo autólogo estéril. Foi realizada a contagem do anel celular em câmara de Neubauer e foi verificada sua viabilidade utilizando corante vital. Neste estudo foi verificado que no volume de MO colhido foi possível obter a média de $2,57 \times 10^{6}( \pm 1,56) \mathrm{CM} \mathrm{kg}^{-1}$ e a viabilidade celular foi superior a $90 \%(96,72 \pm 2,9 \%)$. Concluise que a técnica de colheita de MO com agulha Steis com lavagem celular no meio contendo soro autólogo e Kit Bone Marrow e agulha Steis com lavagem celular no meio contendo soro autólogo permite obter um número ideal e indicado de
$C M$ viáveis. Esse número pode ser aplicado diretamente em lesões teciduais com objetivo de potencializar o processo de regeneração.

Palavras-chave: medula óssea, transplante celular, células mononucleares, modelo experimental, cães.

\section{ABSTRACT}

In the present research a new protocol to harvest $10 \mathrm{ml} \mathrm{kg}{ }^{-1}$ femoral bone marrow (BM) was developed to allow isolation, quantification and to test the mononuclear cell (MC) fraction viability. Forty male or female stray dogs, aging and weighting around two years old and $10 \mathrm{~kg}$ respectively, were submitted to aseptic bone marrow harvest in a surgical environment. To achieve an ideal cell count of MC, an anatomical Steis needle was used during the procedure, which favored the indicated volume harvest in a shorter period of time without interfering cellular viability. A bone marrow collection kit was also used to filter bone fragments while maintaining harvested MC integrity during blood packaging. Meanwhile BM harvesting was conducted, animals peripheral blood collection was performed (pre, trans and post-operatory) to hematological evaluations and autologous blood transfusion was made to overcome the increased hemoglobin fall that takes place in the initial harvesting moments. The harvested and filtered BM was slowly placed over a Histopaque density gradient $\left(1.077 \mathrm{~g} \mathrm{ml}^{-1}\right)$. The material was centrifuged at $440 \mathrm{~g} x$ for 30 minutes. The cellular ring was harvested, washed and three times centrifuged in saline 0.9\%, DMEM and autologous sterile serum. Cellular ring count was conducted in neubauer chamber and its viability was performed with vital dye. In this study was possible to notice that with the harvested BM volume an average of $2.57 \times 10^{6}( \pm 1.56) \mathrm{MC} \mathrm{kg}^{-1}$ was obtained and the cell viability was over $90 \%$ (96.72 $\pm 2.9 \%)$. It was concluded that the bone marrow kit and Steis needle with autologous

IPrograma de Pós-graduação em Medicina Veterinária, Universidade Federal de Santa Maria (UFSM), Santa Maria, RS, Brasil. Email: oldeby@yahoo.com.br. *Autor para correspondência.

IDepartamento de Clínica de Pequenos Animais (DCPA), UFSM, Santa Maria, RS, Brasil.

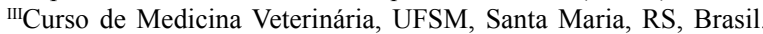


serum cellular wash BM harvesting technique allow an ideal MC number isolation which can be administered in tissue lesions to enhance the regeneration process.

Key words: bone marrow, cell transplantation, mononuclear cells, experimental model, dogs.

\section{INTRODUÇÃO}

Um dos aspectos peculiares da hematologia diz respeito à terapêutica, que inclui não apenas moléculas farmacológicas, mas também as próprias células sangüíneas (GODOY et al., 2006). Para investigar as complexas funções destas células, pesquisadores vêm utilizando a transfusão sangüínea no reparo de lesões teciduais, na melhoria do transporte de oxigênio e na reconstituição da hemostasia (NOORT \& FALKENBURG, 2000). Geralmente, a terapia mais simples consiste na transfusão das células sangüíneas maduras obtidas do sangue circulante (GODOY et al., 2006), pois ela exige apenas o fracionamento do sangue em componentes mononucleares e é extremamente eficaz na reposição de hemácias e plaquetas (BRUGGER. et al., 2000).

A segunda fase da terapia celular nesta especialidade é a transfusão de células progenitoras (CP) contendo a fração total de CM, adquiridas por meio do transplante de MO (KHALDI et al., 2003). Estas são capazes de reconstituir um sistema doente ou danificado e recuperar a função tecidual e receberam o nome de células-tronco (CT) (SANTOS et al., 2004). O transplante de MO para terapia apresenta algumas limitações para sua utilização, como a obtenção da fração total de CM em quantidade suficiente, que exige múltiplas aspirações da $\mathrm{MO}$ em ambiente cirúrgico (GUNSILIUS, 2001). Outro aspecto limitante é o tempo médio para se obter efeito terapêutico depois de transplantadas, cerca de duas a quatro semanas, isto é, para a geração das novas células sangüíneas (PRANKE et al., 2006) ou para o fornecimento dos elementos celulares necessários durante o processo regenerativo como a quimiotaxia e o efeito parácrino em um novo microambiente (LEVENBERG et al. 2003).

$\mathrm{O}$ atual estágio de pesquisas com a fração total de CM contendo CT tem apontado múltiplas possibilidades para a reparação tecidual e a qualidade dos processos regenerativos quando transplantadas células processadas em um volume maior ou igual 2 x $10^{6}$ (SUTER et al., 2004) a $2 \times 10^{8} \mathrm{CM}_{\text {da }} \mathrm{MO}$ por kg-1 $\mathrm{do}$ receptor (NAKAGE et al., 2005). Essa metodologia coloca a questão da utilização terapêutica das CT em bases totalmente novas na medicina veterinária. Existe hoje um grande entusiasmo quanto às possibilidades de empregar CT para tratar numerosas doenças em diversas espécies de animais, principalmente o cão (SUTER et al. 2004). Estudos realizados nesta espécie revelaram fenotipica e funcionalmente semelhanças com a CT de humanos e camundongos, indicando que o modelo canino é aplicável ao estudo de CT para que os resultados possam ser transpostos a outras espécies (SUTER et al., 2004; NARDI; MEIRELLES, 2006).

Apesar das diversas aplicabilidades da terapia celular com adjuvante nas intervenções reconstrutivas na medicina veterinária, ainda não há padronização da técnica de colheita e quantificação das células da MO para obtenção de CM contendo CT hematopoéticas e mesenquimais para aplicabilidade terapêutica na espécie canina. Portanto, o presente estudo teve como objetivo desenvolver uma técnica de colheita de MO utilizando o kit de colheita de MO Bone Marrow Collection Kit e a agulha tipo Steis para obtenção de uma quantidade de CM viável, que poderá ser utilizada em transplantes para tratamento de lesões teciduais em cães.

\section{MATERIAL E MÉTODOS}

O estudo foi desenvolvido no Laboratório de Cirurgia Experimental do Hospital Veterinário da Universidade Federal de Santa Maria. Foram utilizados 40 cães hígidos, sem raça definida, machos e fêmeas, com idades estimadas entre um e dois anos, pesando em torno de $10 \mathrm{~kg}$. Os animais foram mantidos em biotério climatizado com canis individuais apropriados, recebendo água e ração comercial ad libitum desde a fase de adaptação até o final do experimento.

Três dias antes da data de colheita de MO, todos os animais foram submetidos à colheita de sangue periférico $\left(10 \mathrm{ml} \mathrm{kg}^{-1}\right)$, da veia jugular, para autotransfusão transoperatória durante o procedimento de colheita de MO, segundo TOGNOLI et al. (2007), TOGNOLI(2008) e OLIVEIRA (2008). O sangue colhido foi armazenado em bolsas de transfusão sangüínea devidamente datadas e identificadas de acordo com o a numeração do próprio animal, contendo $14 \mathrm{ml}$ de CPDA (citrato de sódio, fosfato, dextrose e adenina) para cada $100 \mathrm{ml}$ de sangue. Depois, as amostras foram refrigeradas em geladeira comum a uma temperatura de $4^{\circ} \mathrm{C}$ até sua utilização.

O pré-operatório constou de jejum alimentar de 12 horas e hídrico de seis horas. Antes da administração da medicação anestésica, colheu-se amostras de sangue periférico: a) $2 \mathrm{ml}$ da veia jugular, para exame de hemograma e análise de hematócrito $(\mathrm{Ht})$, hemoglobina $(\mathrm{Hb})$ e b) $7 \mathrm{ml}$ sem anticoagulante, que foi colocado em tubo de bioquímica de vidro, com 
capacidade para $15 \mathrm{ml}$, previamente esterilizado em autoclave, a $121^{\circ} \mathrm{C}$ por 15 minutos, tampado de forma hermética e enviado ao laboratório de análises clínicas do Hospital Veterinário da UFSM para obtenção do soro autólogo. O sangue foi colocado em banho-maria a $37^{\circ} \mathrm{C}$ por 10 minutos para obter melhor retração do coágulo sangüíneo e depois foi centrifugado a 1800rpm (495 x g) por seis minutos.

Em seguida, efetuou-se a medicação préanestésica composta por acepromazina $\left(0,05 \mathrm{mg} \mathrm{kg}^{-1}\right) \mathrm{e}$ fentanil $\left(0,002 \mathrm{mg} \mathrm{kg}^{-1}\right)$ aplicadas por via intramuscular (IM). A anestesia epidural foi realizada com morfina $\left(0,1 \mathrm{mg} \mathrm{kg}^{-1}\right)$, lidocaína $2 \%\left(0,25 \mathrm{mg} \mathrm{kg}^{-1}\right)$ e bupivacaína $0,25 \%\left(0,25 \mathrm{mg} \mathrm{kg}^{-1}\right)$. A indução anestésica foi realizada com propofol $\left(4 \mathrm{mg} \mathrm{kg}^{-1}\right)$ pela via endoflébica e como manutenção anestésica utilizou-se anestesia geral inalatória com halotano vaporizado em oxigênio a $100 \%$, administrado em circuito semifechado. Para a profilaxia antimicrobiana, foi utilizado cefalotina $\left(30 \mathrm{mg} \mathrm{kg}^{-1}\right)$ por via intravenosa (IV) e para analgesia transoperatória foi administrado parecoxib sódico $\left(2 \mathrm{mg} \mathrm{kg}^{-1}\right)$ (IV). Após a intervenção, todos os animais receberam analgesia com parecoxib sódico $\left(2 \mathrm{mg} \mathrm{kg}^{-1}\right)$ SID durante três dias consecutivos.

Após todos os procedimentos para manipulação asséptica, os animais anestesiados e previamente tricotomizados foram colocados em decúbito lateral direito e submetidos à colheita de sangue da MO. As amostras foram obtidas por punção rotacional e aspiração com o auxílio de agulha anatômica do tipo Steis (15G X 3"). O local de punção foi a fossa trocantérica femoral direita, sendo que em $90 \%$ dos casos foi necessária apenas uma punção óssea para colher a quantidade de medula desejada $\left(10 \mathrm{ml} \mathrm{kg}^{-1}\right)$. As amostras foram colhidas com auxílio de seringas de $10 \mathrm{ml}$ previamente heparinizadas com liquemine (heparina 10.000UI). Para penetrar no espaço medular dos ossos, foi aplicada uma pressão manual, moderada à agulha, girado-a e alternando os movimentos para direita e esquerda. A MO colhida foi transferida para uma bolsa de colheita de MO, Bone Marrow Collection Kit, contendo $0,1 \mathrm{ml}$ de liquemine (heparina $10.000 \mathrm{UI}$ ) e $10 \mathrm{ml}$ solução salina $0,9 \%$ para cada $100 \mathrm{ml}$ de MO. Após o término da colheita, o total de sangue intramedular passou pelo pré-filtro de 850 mícron, seguido de dois filtros, um de 500 micra e o segundo de 200 micra, acoplados em linha, para filtragem das espículas ósseas.

$\mathrm{O}$ total de amostra sangüínea retirada da $\mathrm{MO}$ $\left(10 \mathrm{ml} \mathrm{kg}^{-1}\right)$ de cada animal foi automaticamente transferido para uma bolsa de infusão própria de $\mathrm{MO}$, também acoplada no mesmo kit. Uma alíquota de $1 \mathrm{ml}$ de sangue da MO foi colhida diretamente da bolsa de infusão após a filtragem e encaminhada sob temperatura ambiente ao laboratório de análises clínicas do Hospital Veterinário da UFSM para contagem manual da porcentagem de células nucleadas totais. O cálculo da contagem absoluta de células nucleadas foi realizado por meio da multiplicação da quantidade total de células nucleadas (contagem global de leucócitos) e o volume do sangue da MO colhido. Este número foi dividido pelo peso do paciente, resultando no número total de células nucleadas (BITTENCOURT et al., 2006).

Uma alíquota de $1 \mathrm{ml}$ da medula retirada diretamente do osso femoral no momento da colheita foi separada para confecção de esfregaços para exame de mielograma. Foram confeccionadas por esfregaço 10 lâminas da amostra da MO para análise complementar da atividade hematopoética e morfológica das células do sangue da MO. As lâminas foram coradas por kit panótico rápido, composto de um álcool fixador, um corante eosinofílico e outro basofílico e foram avaliadas de acordo relação mielóide e eritróide de normo, hipo ou hipercelular da MO por microscopia de luz.

A MO colhida $\left(10 \mathrm{ml} \mathrm{kg}^{-1}\right)$ foi centrifugada a 1600 rotações por minuto (rpm) (força centrípeta de $440 \mathrm{~g}$ ) em tubos Falcon de $50 \mathrm{ml}$ e isolada em gradiente de densidade Histopaque $1.077 \mathrm{~g} \mathrm{ml}^{-1}$ (1:1), de acordo com a técnica de Boyum (BOYUM, 1968), mantendo-a a uma temperatura entre $18-26^{\circ} \mathrm{C}$. $\mathrm{O}$ halo contendo as $\mathrm{CM}$, formado depois da centrifugação, foi colhido entre as interfaces lavadas e centrifugadas (5 minutos; $440 \mathrm{x}$ g) três vezes em meio contendo solução salina $0,9 \%$, DMEM (Dulbeco's Modified Eagle's Medium) e soro sangüíneo autólogo estéril, com intuito de remover os agregados celulares, obtendo como produto final o botão celular padronizado em $1000 \mu$ l. Uma pequena fração $(50 \mu 1)$ de CM suspensas foi colhida para contagem manual da porcentagem e quantificação de CM e teste de viabilidade celular por método de exclusão com corante azul de Tripan 1\% (MELO et al., 2003) em lâmina de Neubauer, sendo considerada aceitável uma viabilidade acima de $90 \%$ e um número mínimo de $2 \times 106 \mathrm{~kg}^{-1}$ de $\mathrm{CM} \mathrm{cm}{ }^{2}$ (SUTER et al., 2004). O delineamento experimental foi inteiramente casualizado e as médias foram comparadas por meio do teste " $t$ de Student" ao nível de significância $\mathrm{P} \leq 0,05$. (SNEDECOR; COCHRAN, 1994).

\section{RESULTADOS E DISCUSSÃO}

A transfusão sangüínea em cães, segundo CALLAN (2000), é indicada quando os níveis de $\mathrm{Ht}$ encontram-se abaixo de $15 \%$, já outros autores mencionam 21\% (HARREL et al., 1997). Neste estudo percebeu-se uma leve diminuição do Ht no momento trans e pós $(\mathrm{P} \leq 0,05)$ da colheita de MO (Tabela 1$)$, 
Tabela 1 - Valores médios do eritrograma obtidos durante os momentos pré, trans, pós e 24 horas após a colheita de medula óssea em sangue periférico de cães $(n=40)$.

\begin{tabular}{lllll}
\hline & & & & \\
& & & & \\
& pré & trans & pós & $24 h$ \\
\hline Proteína plasmática g/dL & 7,89 & 6,9 & 7,03 & 7,3 \\
Hemácias uL & 5,44 & 5,40 & 6,16 & 6,10 \\
Hematrócito* \% & 32,4 & 25,7 & 34,18 & 24,25 \\
Hemoblobina* g/dL & 11,02 & 6,76 & 9,91 & 14,8 \\
Reticulócitos* \% & 2,57 & 2,0 & 3,63 & 1,0 \\
Proteína plasmática g/dL & 7,89 & 6,9 & 7,03 & 8,2 \\
\hline
\end{tabular}

permanecendo diminuído 24 horas após a infusão de sangue autólogo $(33,9 \% \pm 11,1)$, resultado similar aos estudos de COHEN \& BRECHER (1995), TOGNOLI (2008) e OLIVEIRA (2008), os quais afirmam que os níveis de $\mathrm{Ht}$ em pacientes submetidos à transfusão sangüínea após coleta de MO decrescem no período pós-operatório. A porcentagem de hematócrito diminuída, mesmo não sendo significativa, pode levar a uma condição de hipóxia tecidual (LOPES et al., 2006).

Na avaliação do hemograma (Tabela 1), foi constatado um aumento significativo no número de reticulócitos circulantes $(\mathrm{P} \leq 0,05)$ a partir da infusão de autotransfusão, diminuindo 24 horas após a colheita de MO. Estes achados vão de encontro às afirmações deFERNANDEZ \& GRINDEM(2000), TOGNOLI(2008) e OLIVEIRA (2008), que observaram uma diminuição gradual dos níveis de reticulócitos logo após uma colheita de MO mesmo quando os níveis de $\mathrm{Ht}$ encontram-se normais ou elevados.

Uma queda na concentração de $\mathrm{Hb}$ em doadores de MO é verificada no período pós-operatório em humanos em cerca de 2 a 2,4g dL ${ }^{-1}$ (MIJOVIC, 2006) e em cães (TOGNOLI et al., 2007; TOGNOLI 2008). Entretanto, neste estudo, foi verificado que os animais apresentaram níveis de $\mathrm{Hb}$ diminuídos em média $6,76 \mathrm{~g}$ $\mathrm{dL}^{-1}(\mathrm{P} \leq 0,05)$ no momento trans do procedimento (Tabela 1). MIJOVIC et al. (2006) afirmam que a transfusão de sangue é necessária somente em pacientes que apresentam os níveis de $\mathrm{Hb}$ inferiores a $12,5 \mathrm{~g} \mathrm{dL}^{-1}$ em humanos e OLIVEIRA (2008) relata essa necessidade quando os níveis de $\mathrm{Hb}$ apresentam os níveis de $10,2 \mathrm{~g} \mathrm{dL}^{-1}$ durante o trans-operatório.

PARKKALI et al. (2005) concluíram que não é necessária a colheita autóloga de sangue para doadores sadios de $\mathrm{MO}$, pois a concentração de $\mathrm{Hb}$ não decresce em níveis constantes e permanentes. Desse modo, os autores afirmam que a autotransfusão pré-operatória ou transoperatória é prática dispendiosa e desnecessária em doadores de pequenos volumes de MO. Todavia, neste estudo, foi verificado que os níveis de $\mathrm{Hb}$ diminuíram em $1,11 \mathrm{~g} \mathrm{dL}^{-1}(\mathrm{P} \leq 0,05)$ no momento imediato pós-transfusão (Tabela 1) e em 1,06g $\mathrm{dL}^{-1}$ mesmo após receberem sangue autólogo, sendo que os níveis normais retornaram após o oitavo dia de avaliação. Essa prática segue a conclusão da pesquisa de TOGNOLI et al.,(2007), os quais observaram que, em condições experimentais, é necessária a realização de autotransfusão sangüínea no período transoperatório em cães submetidos à doação de $10 \mathrm{ml} \mathrm{kg}^{-1}$ de $\mathrm{MO}$, fato este justificado pela queda de $\mathrm{Hb}$ apresentada pelos animais durante o ato da colheita e a elevação imediata após a transfusão.

Todo o procedimento de colheita da MO foi realizado em centro cirúrgico para prevenção de contaminação. Antes da aspiração, as seringas foram lavadas com solução salina $0,9 \%$ associada com liquemine (heparina 10.000UI), pois essa combinação impede a coagulação e evita a formação de bolhas permanentes dentro da bolsa de armazenamento desenvolvida no momento da colheita. Se utilizados anticoagulantes com menor unidade, ocorre coagulação da MO em um curto período de tempo, o que impede o uso terapêutico (BACIPALUGO et al., 1992).

Para iniciar a aspiração, a agulha foi introduzida na pele e posteriormente dentro da fossa trocantérica do osso femoral. A escolha do osso está de acordo com TOGNOLI et al., (2007) pela facilidade de encontrar grande quantidade de CM e pelo fato de que com uma única introdução da agulha no osso femoral consegue-se a quantia desejada, aspirando-se 5 a $7 \mathrm{ml}$ de cada vez. De acordo BACIPALUGO et al (1992), a quantidade de MO com maior número de CP encontra-se na crista ilíaca e são necessárias de quatro a cinco perfurações na pele que são realizadas acompanhando a curvatura das cristas ilíaca superior e inferior em ambos os lados com a agulha. No interior da crista, são realizadas aproximadamente 100 perfurações e o pós-operatório torna-se mais doloroso e dispendioso.

Mesmo que a agulha utilizada apresente diâmetro aparentemente elevado, sabe-se que, por meio dos métodos de estabilização de fraturas, o canal medular pode ser preenchido em 60 a $70 \%$ com pinos de Steinmann, sem que isso acarrete prejuízo vascular ao córtex ósseo (EL-WARRACK \& SCHOSSLER, 1998). Desse modo, neste estudo foi observado que, na introdução da agulha, nenhum cão apresentou o canal medular femoral preenchido com mais de $40 \%$ pela agulha. Clinicamente, de acordo com a tabela proposta por TUDURY \& RAISER (1985), não foi observada manifestação de dor e os cães apresentaram 
grau V de recuperação deambular, 24 horas após o procedimento. A viabilidade da realização desta técnica deve ser ressaltada neste estudo, uma vez que os demais artigos publicados sobre a punção de $\mathrm{MO}$ em crista ilíaca de cães relatam a grande dificuldade de introdução de outros tipos de agulhas e também a dificuldade de se conseguir um volume adequado (FERNANDEZ \& GRINDEM, 2000). A prática de colheita de MO na crista ilíaca de cães é de difícil manejo devido ao formato anatômico do osso e à dificuldade de introdução da agulha, aumentando o tempo da permanência do animal anestesiado e o tempo de colheita do sangue (CAR \& BULE, 1986). Na técnica que foi utilizada neste trabalho, o tempo total de colheita de MO em todos os cães levou um tempo mínimo de 20 minutos e máximo de 30 minutos. De acordo com a técnica de punção de MO para a colheita de CM realizada por SAMOTO (2006), VAZ (2006) e BARROS et al. (2001), a quantidade de sangue obtida por esta via foi inferior a $50 \mathrm{ml}$ e a quantidade de $\mathrm{CM}$ foi inferior a $2 \times 10^{5}$, no entanto, a viabilidade celular foi superior a $90 \%$.

$\mathrm{O}$ equipamento de colheita de MO que foi utilizado contém um recipiente que armazena a medula e possui um filtro de 850 micra acoplado à bolsa e dois outros filtros externos, de 500 e 200 micra, respectivamente, que tem a finalidade de reter as espículas ósseas (DENNEHEY et al., 2007). Admitindose que um número mínimo de $2,5 \times 10^{6}$ células hematopoéticas $\mathrm{kg}^{-1}$ do paciente ou 2,0-4,0 $\times 10^{8}$ células totais nucleadas ou ainda $2 \times 10^{6} \mathrm{CM}$ (GUARITASOUZA et al., 2005) é necessário para obter uma recuperação eficaz e sustentada da hematopoese, esses valores são obtidos quando colhidos entre 10 e $15 \mathrm{ml}$ $\mathrm{kg}^{-1}$ de sangue da MO do doador (MASSUMOTO \& MIZUKAMI, 2000). Neste estudo verificou-se que, no volume coletadohido de $10 \mathrm{ml} \mathrm{kg}^{-1}$ de MO de cada animal $(\mathrm{n}=40)$, conseguiu-se obter a média de 2,57 $\times 10^{6}( \pm 1,56)$, valores de $\mathrm{CM}$ e viabilidade celular superiores a $90 \%$ $(96,72 \pm 2,9 \%)$, garantindo a qualidade da suspensão, resultados muito próximos à pesquisa de GUARITASOUZA et al. (2005), realizada em animais de laboratório, que obtiveram as CM $\left(3 \times 10^{6}\right)$ pela técnica de Boyum (1968), em que a suspensão de MO foi diluída e centrifugada a $1400 \mathrm{rpm}$ por 40 minutos com alta viabilidade do botão celular.

É preciso destacar que, de um total de 40 (n) animais, $12(30 \%)$ apresentaram valores celulares inferiores ao mínimo desejado $(\mathrm{P}>0,05)$, mas com viabilidade acima de $90 \%(\mathrm{P}=0,05)$. Apesar de nenhuma falha da hematopoese observada, a mobilização das CM na MO foi mínima e, em condições normais, um aumento significativo de CM poderia ser resgatado se no manejo pré-colheita de MO os animais fossem estimulados por meio da mobilização tanto medular como periférica, com fatores de crescimento como Filgrastima (granulokine $0,6 \mathrm{~m} 1 \mathrm{~min}^{-1} \mathrm{~kg}^{-1} \mathrm{em}$ uma ou até três aplicações) ou ainda combinações com citoquinas hematopoéticas (G-CSK ou GM-CSF) (LUCIDI \& TAKAHIRA, 2007). O exame de imunofenotipagem realizado por citometria de fluxo para a detecção ou a identificação de subtipos dessas células poderia gerar um resultado quantitativo com maior margem de segurança e, desse modo, um número substancialmente maior de células poderia ser obtido.

As amostras de medula colhidas na primeira punção para análise morfológica e estrutural de todos os cães tiveram como objetivo avaliar a presença de células hematopoéticas maduras, ancoradas na MO para caracterizar a colheita da medula e também para diagnóstico de doenças hematológicas se houvessem, assim como estudo do tecido medular. De acordo com DIELBOLD et al. (2000), o mielograma fornece dados importantes de modo melhor que a citologia, como, por exemplo, o grau de atividade da celularidade medular e o diagnóstico de mielofibrose e mieloesclerose. $\mathrm{Na}$ análise microscópica de todas as amostras deste estudo, coradas com hematoxilina e eosina, foi confirmada a origem medular das células. Uma vez confirmada a origem, foi considerada a presença de células sangüíneas e não se observou alteração da estrutura e da morfologia dessas células nas leituras das lâminas.

O maior desafio da manipulação celular é a manutenção das características funcionais das células colhidas e a manutenção da vitalidade. Os protocolos existentes para lavagem, nutrição e manutenção celular possuem uma mistura enriquecida com sais minerais, aminoácidos e componentes essenciais e proteínas de soro fetal bovino. Para baratear os custos deste estudo, utilizou-se, para cada animal, o soro autólogo estéril, que contém água $(92 \%)$, proteínas $(7 \%)$ e outras substâncias como hormônios e enzimas (1\%) e DMEM com intuito de fornecer energia às $\mathrm{CM}$ durante a lavagem e a obtenção do botão celular. Percebeu-se que a viabilidade celular manteve-se acima de $90 \%$, mas é preciso aprofundar os estudos para verificar a expressão do núcleo celular quanto a mitoses. $\mathrm{O}$ sucesso do transplante de medula utilizando a fração total de CM da MO depende em parte da quantidade de células precursoras empregadas por quilo de peso do receptor. Esse fator é limitante e uma maneira de tentar contorná-lo é amplificar ainda mais a população de células precursoras resgatadas antes da transfusão. 


\section{CONCLUSÕES}

Toda a colheita de MO deve ser realizada em centro cirúrgico de forma asséptica e antisséptica, pois é um procedimento que afeta a imunidade animal e acarreta alterações hematológicas. De acordo com os resultados obtidos neste estudo, sugere-se que a transfusão sanguínea deve ser realizada durante a colheita de grande volume de MO devido a alterações nos níveis de hemoglobina. A técnica de colheita de MO com Bone Marrow collection Kit e agulha Steis é um método rápido e eficaz e proporciona a obtenção de um botão celular com alta viabilidade. Portanto, os autores indicam esta técnica como meio de fonte abundante de CM necessárias para explorar sua aplicação terapêutica sob a forma de implante celular em um novo microambiente.

\section{AGRADECIMENTOS} e Tecnológico $(\mathrm{CNPq})$.

Conselho Nacional de Desenvolvimento Científico

\section{FONTES DE AQUISIÇÃO}

${ }^{a}$ Agullha Steis - Tucumedy - Marthan- Med Tec -Popper ${ }^{\circledR}$ PBN- M.D. Tech- Porto Alegre- RS.

${ }^{\mathrm{b}}$ Kit Bone Marrow - Fenwal ${ }^{\mathbb{Q}}$ - Baxter (Baxter Hospitalar Ltda) - São Paulo-SP.

\section{COMITÊ EM ÉTICA E BIOSSEGURANÇA}

Todos os procedimentos foram realizados de acordo com os princípios éticos da experimentação animal, conforme recomendação do Colégio Brasileiro de Experimentação Animal (COBEA). O projeto foi aprovado pelo Comitê em Ética Animal da UFSM, sendo registrado sob o número 23081.010242/200739.

\section{REFERÊNCIAS}

BACIPALUGO, A. et al. Bone marrow harvest for marrow transplantation: effect of multiple small $(2 \mathrm{ml})$ or large $(20) \mathrm{ml}$ aspirates. Bone marrow Transplantation, v.9, n.1, p. 467$470,1992$.

BARROS, S.V.S.G. et al. Autoenxerto percutâneo de medula óssea em coelhos. I coleta, preparo e aplicação. Ciência Rural, v.31, n.6, p.1013-1018, 2001.

BITTENCOURT, R.A.C. et al. Isolation of bone marrow mesenchymal stem cells. Acta Ortopédica Brasileira, v.14, n.1, p. 22-24, 2006.

BOYUM, A. Separation of leukocytes rom blood and bone marrow. Introduction. Scand. Journal Clinical Laboratory Investigation Supplement, v.97, p.7, 1968.

BRUGGER, W. et al. Ex vivo manipulation of hematopoietic stem and progenitor cells. Seminars in Hematology, v.37, n.2, p.42-49, 2000.
CALLAN, M.B. Red blood cell transfusions in the dog and cat. In: FELDMAN, B.F. et al. Schalm's veterinary hematology. Philadelphia: Lippincott Williams \& Wilkins, 2000. Cap.123. p.833-837.

CAR, B.D.; BLUE, J.T. Approaches to evaluation of bone marrow function. In: FELDMAN, B.F. et al. (Eds.). Schalm's veterinary hematology. 5.ed. Philadelphia : Lea \& Febiger; 1999. Cap.2, p.33-35.

COHEN, J.A.; BRECHER, M.E. Preoperative autologous blood donation: benefit or detriment? A mathematical analysis. Transfusion, v.35, n.8, p.640-644, 1995.

DENNEHEY, T. et al. Bone marrow kit. Capturado em 05 dez. 2007. On line. Disponível na Internet http:// www.freepatentsonline.com/6523698.html.

DIELBOLD, J.M. et al. Bone marrow manifestations of infections and systemic diseases observed in bone marrow trephine biopsy. Histopathology; v.37, p.199-211. 2000.

EL-WARRAK, A.O.; SCHOSSLER, J.E. Osteossíntese diafisária de tíbia em cães mediante inserção intramedular de pinos de Steinmann pela crista tibial. Ciência Rural, v.28, n.1, p.7782,1998

FERNANDEZ, F.R.; GRINDEM, C.B. Reticulocyte response. In: FELDMAN, B.F. et al. Schalm's veterinary hematology. Philadelphia: Lippincott Williams \& Wilkins, 2000. Cap.19. p.110-116.

GODOY, A.V. et al. Electrophoretic profile of serum proteins from the umbilical chord blood of dogs. Ciência Rural, v.36, n.2, p.531-535, 2006.

GUARITA-SOUZA, L.C. et al. Comparision of mononuclear and mesenchymal stem cell transplantation in myocardium infaction. Brazilian Journal Cardiovascular Surgery, v.20, n.3, p.270-278, 2005.

GUNSILIUS, E. et al. Hematopoietic stem cells. Biomedicine Pharmacotherapy, v.55, p.186-194, 2001.

HARREL, K. et al.. Canine transfusion reactions. Part II. Prevention and treatment. Compendium on Continuing Education for the Practicing Veterinarian, v.19, n.2, p.193-200, 1997.

KHALDI, A.A. et al. Therapeutic angiogenesis using autologous bone marrow stromal cells: improved blood flow in a chronic limb ischemia model. Annals of Thoracic Surgery. v.75, p.204-209, 2003.

LOPES et al. Reticulócitos e hematócrito de cães pré e pós esplenectomia parcial. Ciência Rural, v.36, n.3, p.1000$1003,2006$.

LUCIDI, C.A.; TAKAHIRA, R.K. Granulocyte colonystimulating factor use in neutropenias in dogs and cats. Ciência Rural, v.37, n.3, p.915-920, 2007.

MASSUMOTO, C.; MIZUKAMI, S. Autologous boné marrow transplantation and posttransplant immunotherapy. Medicina, Ribeirão Preto, v.33, p.405-414, 2000. 
MELO, D.F. et al. Viabilidade das células mononucleares do sangue periférico humano em diferentes meios de estocagem de dentes avulsionados. Acta Scientiarum Health Sciences, v.25, n.1, p.69-74, 2003.

MIJOVIC, A. et al. Preoperative autologous blood donation for bone marrow harvests: are we wasting donors' time and blood? Transfusion Medicine, v.16, p.57-62, 2006

NAKAGE, A.P.; SANTANA, A.E. Hematopoietic stem cells in dogs. Ciência Rural, v.36, n.1, p.325-329, 2006.

NARDI, N.B.; MEIRELLES, L.S. Mesenchymal stem cells: Isolation in vitro expansion and characterization. Handbook Experimental Pharmacology. v.174, p.249-282, 2006.

NOORT, W.A.; FALKENBURG, J.H.F. Haematopoietic content of cord blood. In: COHEN, S.A.A. et al. Cord blood caracteristics: role in stem cells transplantation. London, Martin Dunitz, 2000. p.13-37.

OLIVEIRA， G.K. Células-tronco mononucleares autólogas na cicatrização de defeitos tibiais agudos experimentais de cão. 2008. 50f. Dissertação (Mestrado em Medicina Veterinária) - Universidade Federal de Santa Maria, Santa Maria.

PARKKALI, T. et al. Collection of autologous blood for bone marrow donation: how useful is it? Bone Marrow Transplantation, v.35, p.1035-1039, 2005.

PRANKE, P. et al. Comparative quantification of umbilical cord blood CD34+ and CD34+ bright cells using the ProCount -BD and ISHAGE protocols. Brazilian Journal of Medical and Biological Research, v.39, p.901-906, 2006.

SAMOTO, V.Y. Terapia celular cardíaca: vias de infusão de células mononucleares em cães s.r.d. 2006 . $105 \mathrm{f}$
Dissertação (Mestrado em Ciências) - Faculdade de Medicina Veterinária e Zootecnia da Universidade de São Paulo.

SANTOS, R.R. et al. Bone marrow cells transplant in the treatment of chronic chagasic cardyomyopathy. Revista Brasileira de Medicina Tropical, v.37, n.6, p.490-495, 2004

SUTER, S.E. et al. Isolation and characterization of pediatric canine bone marrow CD34+ cells. Veterinary Immunology and Immunopathology, v.101, p.31-47, 2004

SNEDECOR, G.W.; COCHRAN, W.G. Statistical methods. 8.ed. Ames: Iowa State University, 1994. 503p.

TOGNOLI, G.K. Autotransplante da fração mononuclear da medula óssea em úlcera corneana por hidróxido de sódio experimental em cães. 2008. 51f. Dissertação (Mestrado em Medicina Veterinária) - Universidade Federal de Santa Maria.

TOGNOLI, G.K. et al. Autotransfusão sangüínea na colheita de medula óssea em cães. In: SIMPÓSIO MULTIDISCIPLINAR SOBRE CÉlULAS-TRONCO, 2., 2007, São Paulo, SP. Anais... São Paulo: Universidade Federal de São Paulo, 2007. v.2. 60p. p. 31-32.

TUDURY, E.A.; RAISER, A.G. Redução de fraturas distais do fêmur de cães, empregando dois pinos de Steinmann em substituição aos de Rush. Revista Centro de Ciências Rurais, v.15, n.2, p.141-155, 1985.

VAZ, C.E.S. Avaliação do efeito de centrifugado osteogênico de medula óssea na consolidação de fratura: estudo experimental em coelhos. 2006. 109f. Tese (Doutorado em Ciências) - Faculdade de Medicina da Universidade de São Paulo. 